\title{
Premature ovarian failure could be an alarming sign of polyglandular autoimmune dysfunction
}

\author{
Saif A, Assem M \\ Internal Medicine Department, Cairo University, Egypt \\ E-mail: aasem.saif@kasralainy.edu.eg
}

\begin{abstract}
A 31-year-old lady, diagnosed to have premature ovarian failure in the gynecology clinic, was referred for endocrine assessment because of an abnormal thyroid function test. Clinical examination revealed hypotension, and fungal skin infection under her atrophic breasts. Thyroid stimulating hormone (TSH) level was very high. Assessment of the suprarenal function revealed evidence of Addison's disease. Polyglandular autoimmune dysfunction was diagnosed. She was treated with prednisone, fludrocortisone, and levothyroxine with significant improvement of her general condition and blood pressure.
\end{abstract}

Key words: ovarian failure, polyglandular autoimmune syndrome, hypothyroidism, adrenal failure

Polyglandular autoimmune syndromes (PAS) are series of disorders characterized by autoimmunity against two or more endocrine organs and clinical diversity (Saif 2016). Schmidt first described the association between lymphocytic thyroiditis and adrenocortical dysfunction in 1926 (Betterle et al. 2004). Later the syndromes were classified into a rare juvenile type (PAS I) and a relatively common adult type with (PAS II) or without (PAS III) adrenal dysfunction (Kahaly 2009). Premature ovarian failure (POF) may also have an autoimmune origin and when accompanied by other autoimmune endocrinopathies, may be part of the PASs. A case of PAS presenting by POF is discussed herein.

\section{Subject and Results}

A 31-year-old woman, diagnosed to have POF in the gynecology clinic, was referred for endocrine assessment because of an abnormal thyroid function test. She is married and has one child, born six years ago. She lactated normally for 18 months, but started to complain of amenorrhea shortly after delivery. Thyroid functions were not checked before or during pregnancy. Five years after delivery, she was assessed in the gynecology clinic and diagnosed to have premature ovarian failure. She was already on levothyroxine $(0.1 \mathrm{mg}$ daily for two weeks) before being seen in the endocrinology clinic. Clinical assessment revealed weight of $54 \mathrm{~kg}$, blood pressure $85 / 50 \mathrm{mmHg}$ (reported to be $110 / 70 \mathrm{mmHg}$ in the gynecology clinic) and regular pulse $70 / \mathrm{min}$. Oral candidiasis and fungal skin infection under her atrophic breasts were evident. Gonadotropin levels were significantly high and estradiol level was very low. TSH level was very high $(100 \mathrm{mIU} / \mathrm{ml})$ and free thyroxine (FT4) was low. Thyroid peroxidase (TPO) antibodies were positive. Assessment of suprarenal function revealed evidence of Addison's disease. Morning cortisol level was $60.7 \mathrm{nmol} / 1$ (normal range: $138-690 \mathrm{nmol} / \mathrm{l}$ ) with ad-

Corresponding author: Prof. Aasem Saif, 99 El-Manial Street, Cairo 11451, Egypt; phone: 00201222131204; fax: 0020223630039; e-mail: aasemsaif@yahoo.com, aasem.saif@kasralainy.edu.eg. 
Table 1

Assessed parameters before and after treatment.

\begin{tabular}{lccc}
\hline Parameter & $\begin{array}{c}\text { Normal } \\
\text { range }\end{array}$ & $\begin{array}{c}\text { Before } \\
\text { treatment }\end{array}$ & $\begin{array}{c}\text { After } \\
\text { treatment }\end{array}$ \\
\hline $\begin{array}{l}\text { Body weight } \\
\text { (kg) }\end{array}$ & - & 54 & 69 \\
$\begin{array}{l}\text { Blood pressure } \\
\text { (mmHg) }\end{array}$ & - & $85 / 50$ & $110 / 70$ \\
$\begin{array}{l}\text { TSH } \\
\text { (mIU/ml) }\end{array}$ & $0.3-4.5$ & 100 & 3.39 \\
$\begin{array}{l}\text { FT4 } \\
\text { (ng/dl) }\end{array}$ & $0.8-1.8$ & 0.6 & 1.1 \\
$\begin{array}{l}\text { Cortisol } \\
\text { (nmol/l) a.m. }\end{array}$ & $138-690$ & 60.7 & $*$ \\
$\begin{array}{l}\text { ACTH } \\
\text { (pg/ml) a.m. }\end{array}$ & $10-50$ & 69 & 29 \\
\hline $\begin{array}{l}\text { Prolactin } \\
\text { (ng/ml) }\end{array}$ & $2-29$ & 49 & 2.8 \\
\hline $\begin{array}{l}\text { Serum potassium } \\
\text { (mmol/l) }\end{array}$ & $3.5-5.3$ & 5.7 & 5.0 \\
\hline TSH - thyroid & & & \\
\hline
\end{tabular}

TSH - thyroid-stimulating hormone; FT4 - free thyroxine; ACTH - adrenocorticotropic hormone

* - not measured

renocorticotropic hormone (ACTH) 69 pg/ml (normal range: $10-50 \mathrm{pg} / \mathrm{ml}$ ). Peak cortisol level $30 \mathrm{~min}$ after ACTH stimulation was $176.6 \mathrm{nmol} / \mathrm{l}$ (normal $>496.5 \mathrm{nmol} / \mathrm{l}$ ). Serum prolactin level was $49 \mathrm{ng} / \mathrm{ml}$ (normal range: 2-29 $\mathrm{ng} / \mathrm{ml}$ ). Her fasting blood glucose was $83 \mathrm{mg} / \mathrm{dl}$, serum calcium was $8.8 \mathrm{mg} / \mathrm{dl}$ and serum potassium was $5.7 \mathrm{mmol} / \mathrm{l}$. Her liver and kidney functions were normal. Polyglandular autoimmune dysfunction was diagnosed. She was treated with prednisone and fludrocortisone with significant improvement of her general condition and blood pressure. Levothyroxine was stopped temporarily and restarted after two weeks. The dose titration was done over 8 months according to clinical and laboratory follow up. Finally, she was kept on prednisone (2.5 mg twice daily), fludrocortisone (0.1 mg once daily), and levothyroxine ( $0.125 \mathrm{mg}$ once daily). Her blood pressure was up to $110 / 70 \mathrm{mmHg}$ and body weight increased gradually to $69 \mathrm{~kg}$. TSH gradually dropped down to $3.39 \mathrm{mIU} / \mathrm{ml}$, serum prolactin to $2.8 \mathrm{ng} / \mathrm{ml}$, and serum potassium to $5.0 \mathrm{mmol} / \mathrm{l}$. Oral candidiasis was treated with miconazole oral gel. The fungal skin infection resolved completely on clotrimazole skin cream.

\section{Discussion}

The polyglandular autoimmune syndromes are characterized by the coexistence of at least two autoimmune mediated endocrinopathies. PAS I often appears early in the life with persistent candida infection of the skin and mucous membranes. It usually manifests later with hypoparathyroidism or Addison's disease (Eisenbarth and Gottlieb 2004). PAS II usually peaks between ages 20-60 years and multiple generations are affected by one or more component of the syndrome (Neufeld et al. 1980). Type 1 diabetes is often its first symptom and is usually associated with either autoimmune thyroid disease and/or adrenal failure. A third subtype, which does not involve the adrenal cortex, has also been described in adults (Kahaly 2009).

Our patient was diagnosed in the gynecology clinic as a case of a premature ovarian failure. The discovery of an abnormal thyroid function test was the first clue to the presence of multiple endocrinopathies. The very high TSH and the presence of positive TPO antibodies established the diagnosis of Hashimoto's thyroiditis causing primary hypothyroidism. The fact that her blood pressure dropped after taking levothyroxine for two weeks pointed to the possibility of adrenal failure. This was later confirmed by ACTH stimulation test.

The presence of candida infection of the skin and mucous membranes in addition to the primary ovarian failure suggested the diagnosis of PAS I. But the late onset and the absence of hypoparathyroidism did not confirm that possibility. On the other hand, the age of onset of hypothyroidism and adrenal dysfunction, in association with the ovarian failure, pointed towards PSA II. But the muco-cutaneous candidiasis speaks against this possibility. Balamurugesan and Viswanathan (2016) reported the case of a 27-yearold lady who presented with primary infertility and later diagnosed to have PAS II. Despite the importance of reaching a final diagnosis, the recognition of the multiple endocrine deficiencies was the cornerstone of the life-saving management.

In summary, premature ovarian failure could be an alarming sign of multiple endocrine dysfunction. The management of those patients should be handled by a multi-disciplinary team including gynecology and endocrinology specialists. Full assessment of possible other endocrine disease associations would be recommended. 


\section{References}

Balamurugesan K, Viswanathan S. Schmidt syndrome presenting as primary infertility. Journal of case Reports 6, 4-7, 2016.

Betterle C, Lazzarotto F, Presotto F. Autoimmune polyglandular syndrome Type 2: the tip of an iceberg? Clin Exp Immunol 137, 225-233, 2004.

Eisenbarth GS, Gottlieb PA. Autoimmune polyendocrine syndromes. N Engl J Med 350, 2068-2079, 2004.

Kahaly GJ. Polyglandular autoimmune syndromes. Eur J Endocrinol 161, 11-20, 2009.

Neufeld M, Maclaren N, Blizzard R. Autoimmune polyglandular syndromes. Pediatr Ann 9, 154-162, 1980.

Saif A. Polyglandular dysfunction in patients with Type 1 Diabetes: Recurrent hypoglycemia is an alarming symptom. Clin Diabetes 34, 113-114, 2016. 